\title{
Múltiplas Vozes e Múltiplos Sentidos do Pertencimento Étnico: estudo de remanescentes indígenas Kiriris e Payayás
}

\author{
Leila Damiana Almeida dos Santos Souza ${ }^{1}$ \\ Kleber Peixoto de Souza ${ }^{2}$
}

\begin{abstract}
Resumo: Apresentamos nesse artigo aspectos epistemológicos que contribuem para análise da constituição da identidade étnica de um dos grupos humanos que compõe a diversidade dos remanescentes dos povos indígenas Kiriris e Payayás, no distrito de Missão do Sahy, em Senhor do Bonfim, Bahia. Metodologicamente nos valemos da história oral para nos aproximarmos dos processos constitutivos dos remanescentes indígenas e, consequentemente, contribuirmos para o fortalecimento cultural dos ascendentes dos Kiriris e Payayás que ali residem. Os resultados nos apontam que, por meio de uma ação dialógica, foi possível contribuir com o processo de construção da identidade étnica dos sujeitos envolvidos.
\end{abstract}

Palavras-chave: Dialogia. Identidade Étnica. Remanescentes Indígenas.

\section{Multiple Voices and Multiple Senses of Ethnic Belonging: a study of Kiriris and Payayás indigenous remnants}

\begin{abstract}
In this article we present epistemological aspects that contribute to the analysis of the constitution of the ethnic identity of one of the human groups that make up the diversity of the remnants of the Kiriris and Payayás indigenous peoples, in the district of Missão do Sahy, in Senhor do Bonfim, Bahia. Methodologically, we use oral history to approach the constitutive processes of the indigenous remnants and, consequently, contribute to the cultural strengthening of the ancestors of the Kiriris and Payayás who reside there. The results show us that, through a dialogical action, it was possible to contribute to the process of building the ethnic identity of the subjects involved.
\end{abstract}

Keywords: Dialogy. Ethnic Identity. Indigenous remnants.

\section{Múltiples voces y múltiples sentidos de pertenencia étnica: un estudio de los remanentes indígenas Kiriris y Payayás}

Resumen: En este artículo presentamos aspectos epistemológicos que contribuyen al análisis de la constitución de la identidad étnica de uno de los grupos humanos que componen la diversidad de los remanentes de los pueblos indígenas Kiriris y Payayás, en el distrito de Missão do Sahy, en Senhor do Bonfim, Bahía. Metodológicamente, utilizamos la historia oral para acercarnos a los procesos constitutivos de los remanentes

\footnotetext{
${ }^{1}$ Doutora em Cultura e Sociedade. leila.damiana@ufrb.edu.br. Universidade Federal do Recôncavo da Bahia. Orcid: https://orcid.org/0000-0001-8491-2194.

2 Mestre em Educação. kleberpxt@gmail.com. Universidade Federal do Recôncavo da Bahia. Orcid: https://orcid.org/0000-0003-4940-1465.
} 
indígenas y, en consecuencia, contribuir al fortalecimiento cultural de los ancestros de los Kiriris y Payayás que allí residen. Los resultados nos muestran que, a través de una acción dialógica, fue posible contribuir al proceso de construcción de la identidad étnica de los sujetos involucrados.

Palabras clave: Dialogía. Identidad étnica. Restos indígenas.

\section{Introdução}

O estudo apresentado tem sua gênese nas nossas vivências pedagógicas, enquanto docentes de Universidade Pública, e no diálogo estabelecido com professores, alunos e membros da comunidade de Missão do Sahy, um distrito da cidade de Senhor do Bonfim, Bahia.

As ações e reflexões proporcionadas pela presente ação investigativa se tornaram possíveis quando nos aproximamos dos processos de construção da identidade de um grupo de jovens da Escola Municipal Antônio Bastos de Miranda, em Missão do Sahy. Nas ações investigativas, as narrativas dos alunos remanescentes e seus familiares possibilitaram a ampliação da concepção de homem, de cidadania, de meio ambiente e de prática educativa, bem como nos permitiu contribuir para o fortalecimento do pertencimento étnico dos remanescentes indígenas que ali vivem.

A partir dessa inserção numa escola pública, especificamente com jovens remanescentes que não tem nos seus processos educativos ações intencionais voltadas para o pertencimento étnico, acreditamos ser necessário a reorientação da visão de mundo e o desenvolvimento de uma reeducação que leve os indivíduos a se perceberem como parte de uma comunidade que é local e global ao mesmo tempo. Nesse sentido, evidenciamos o que diz Moacir Gadotti (2000) ao defender que uma educação que considere as vivências e histórias dos indivíduos deve ser promotora da "aprendizagem das coisas a partir da vida cotidiana". Uma educação que seja revestida de um componente educativo que prime por uma abordagem ampliada de preservação do homem e do meio em que vive.

Portanto, ao fazer emergir histórias e aspectos culturais de remanescentes indígenas a partir da vida cotidiana e das suas memórias, o objetivo da investigação foi instaurar uma dialogia dialética (BAKHTIN, 1997a) que conduzisse o fortalecimento da identidade étnica dos sujeitos, permeado por um processo onde as múltiplas vozes (polifonia) e os múltiplos sentidos (polissemia) se entrelaçam. Para tanto, metodologicamente nos valemos das entrevistas narrativas como forma de mediar os 
diálogos que estabelecemos com os sujeitos da comunidade acerca do seu pertencimento étnico.

Guiados por essas pretensões metodológicas e epistemológicas, nosso estudo ancora-se numa perspectiva dialógica que pensa o ser humano dentro do seu contexto social e político. Nos valemos da pesquisa qualitativa que, segundo Minayo (1999), é operacionalizada quando os indivíduos estão inseridos em uma determinada condição social, implicados em significados de valores e crenças, sendo estes, fruto de um determinado grupo social.

Para analisarmos o alcance das nossas ações formativas/investigativas optamos pela abordagem etnográfica, onde a etnopesquisa nos deu suporte ao trabalharmos com as realizações práticas instituintes que foram produzindo e instituindo os fatos sociais (MACEDO, 2004). Assim, a etnopesquisa nos oportunizou instituir um novo olhar dos/para os remanescentes indígenas em Missão do Sahy. Portanto, nossa ação investigativa se organizou de modo que nos possibilitasse compreender em que medida os contextos e as narrativas, ancoradas por um processo dialógico, fortaleceriam os processos identitários dos povos remanescentes dos indígenas Kiriris e Payayás e em Missão do Sahy.

As trocas estabelecidas com os estudantes, professores (as) e membros da comunidade foram por nós denominadas de Construções Dialógicas Constitutivas. Denominamos assim essas ações educativas/investigativas por entendermos que foram importantes sinalizadoras dos processos tanto de pertencimento quanto de negação étnica, pois, a partir dos nossos diálogos emergiram aspectos culturais e memórias que permitiram nossa aproximação com os remanescentes indígenas, mais, principalmente, a "aproximação" desses consigo e com seus ancestrais. Portanto, os diálogos foram construtivos e constitutivos.

Esses diálogos nos levaram a compreensão de que o fortalecimento cultural permitiu aos sujeitos perceberem-se como parte do meio ambiente que o cerca e que ao olhar para história que os constituem abre uma possibilidade para mudança de atitude com o outro e com o universo. Nesse sentido, a perspectiva marxista, bakhtiniana e gramsciniana contribuem com nossas análises quando focamos nos processos de transformações dos indivíduos e das condições sociais em que vivem, transformações essas mediadas pelo processo dialógico. 


\section{Missão do Sahy: contextos e histórias}

O distrito Missão do Sahy é uma comunidade que, informalmente, é reconhecida como remanescente de indígenas, mas, formalmente, esse reconhecimento sempre esbarrou em resistências, seja dos órgãos governamentais ou dos próprios membros da comunidade. Por um lado, reconhecer a Missão do Sahy como território de povos tradicionais implicaria tocar num ponto nevrálgico, a ocupação e posse de terras. Por outro lado, gradativamente os moradores foram se afastando da sua ancestralidade e, consequentemente, as novas gerações não se reconhecem como descendentes.

Entendemos que, se existe uma necessidade de afirmação dessa comunidade, nossa contribuição passaria pelo registro de alguns vestígios e fatos que ligam o distrito à ancestralidade dos povos originários que ali viveram. Segundo Maria da Paz e Marlúcia Menezes Paiva, a missão chamada “do Sahy” é resultado da várias transformações, negações e esquecimentos dos povos que ali viveram e vivem.

\footnotetext{
Nesses três séculos de seu povoamento consumou-se o processo de ocupação e, em seguida, a consolidação cultural da ação transformadora, por parte das instituições religiosas; Através da assimilação da nova cultura, foram sendo afastadas e relegadas à ignomínia e ao esquecimento dos ritos e costumes dos povos ali existentes. E paulatinamente foi introjetando o modo de viver do colonizador e tomou forma o processo de esquecimento da história econômica, social, política e cultural do lugar. Na verdade, no atual Município de Senhor do Bonfim, muito pouco se sabe da missão franciscana de Nossa Senhora das Neves do Sahy, bem como da existência da tribo que deu origem ao povoado. (DA PAZ E PAIVA, 2008, p. 2).
}

Nesse processo de afirmação/negação o contexto que cerca a Missão do Sahy é muito peculiar. Habitada originalmente por indígenas, se constituiu a partir Missão religiosa católica e já foi sede da comarca da região. Tem um patrimônio histórico interessante, mas pouco preservado e valorizado, seja pelos poderes públicos seja pelos próprios sujeitos a quem foram legadas essas memórias.

Ao focar os contextos e narrativas da comunidade remanescente tivemos a pretensão buscar nos registros históricos fatos que possibilitassem aos sujeitos que colaboraram na investigação um novo olhar sobre si e sobre o seu passado. Um breve recorte histórico nos permite chegar a fatos que relacionam a presença de povos tradicionais próximos à Missão do Sahy, foram eles os Kariri's. Hoje, os órgãos governamentais atestam que povos dessa etnia habitam diferentes municípios do norte 
do estado da Bahia. Dentre as atuais 30 Terras Indígenas (TI) registradas na Bahia, a Fundação Nacional do Índio (Funai), órgão indigenista oficial do Estado brasileiro, reconhece como regularizadas - aquelas que o processo de demarcação foi concluído três Terras Indígenas Kiriri nos municípios de Banzaê, Quijingue e Ribeira do Pombal.

Os registros históricos relacionados à Missão do Sahy relatam que foram catequizados e escravizados por volta do ano 1703 pela Missão Franciscana de São Gonçalo do Salitre, no atual município de Campo Formoso, distante apenas $16 \mathrm{~km}$ de Senhor do Bonfim (MACHADO, 2007; GONÇALVES, 1997; FREITAS, 2001). Já os Payayás foram indígenas que viveram nas terras a $28 \mathrm{~km}$ de Missão de Sahy, em Itapicuru de Cima, entre os anos de 1689 e 1834, tendo os Freis Capuchinhos como dirigentes da Missão Santo Antônio e Nossa Senhora da Saúde. Também é registrada presença desta etnia nos atuais municípios de Jacobina e Campo Formoso.

Sabemos que em todo território brasileiro a colonização se estabeleceu sobre sangrentas batalhas entre bandeirantes e indígenas. Aliado a essa investida dos bandeirantes as ações missionárias católicas, através dos religiosos da Companhia de Jesus e de outros, buscavam estreitar os laços entre o nativo e o colonizador, com a incumbência (ou pretexto) de converter o primeiro à religião católica e, assim, salvarlhe a alma.

Outros fatores determinantes para a ocupação do território foi a criação e deslocamento do gado e a corrida pelo ouro e pedras preciosas. Estes fatores constituíram o pano de fundo inicial da conquista e colonização do norte e nordeste do estado da Bahia.

Baseado nos fatos históricos temos que o povoado de Missão do Sahy, localizado à $8 \mathrm{Km}$ do centro da cidade de Senhor do Bonfim, pertencia originalmente ao território denominado de Jacobinas. Este se estendia das terras próximas ao Rio São Francisco até Rio de Contas (MACHADO, 2007).

Os registros indicam que a comunidade começa a se constituir com os indígenas Kiriris e Payayás e que, a partir da chegada dos portugueses por volta do século XVII passaram a ser alvo da exploração de mão de obra escrava para as fazendas de gado dos Guedes de Brito (DA PAZ, 2004). Em 1697 os frades da Ordem Franciscana fundaram a missão de Nossa Senhora das Neves do Sahy, para proteção, cristianização e "educação" dos indígenas que restaram do genocídio perpetrado pelos colonos alguns 
anos antes, sob autorização da casa da Torre dos Garcia D’Ávila (DA PAZ, 2009). Supõe-se que a partir daí as comunidades indígenas tenham abraçado a cultura européia, perdendo muito dos seus próprios costumes.

Registra-se que em 1721 o frade capuchinho Martin de Nantes impediu a prisão e o transporte de todos os indígenas da aldeia por Garcia D’Ávila, dono das fazendas da região, para serem vendidos como escravos aos senhores de engenho.

Em julho de 1722 a missão foi elevada à categoria de Vila, tornando-se a primeira na região, que era um espaço administrativo da Coroa Portuguesa para a cobrança de impostos, combate à violência, administração da justiça e das leis. Dois anos depois, porém perdeu tal posto, por conta da distância das recém-descobertas minas de ouro, próximas à missão do Bom Jesus da Glória, atual município de Jacobina.

Em 1841 todos os bens da Missão foram confiscados e devolvidos ao último Frade. Até hoje, não se tem registros do que foi feito com tais bens. Esquecida e quase sem importância, o que restou do antigo aldeamento franciscano foi extinto em 1864.

Hoje são poucos os vestígios dessa história. Os monumentos que restaram (o cemitério e a capela, que foi reconstruída) estão mal preservados e a história oral, passada entre as gerações corre sério risco de extinção, por conta da morte dos mais velhos e do desinteresse das gerações mais novas.

Buscando contribuir com o fortalecimento dos processos constitutivos dessa comunidade é que nos encorajamos a investigar os vestígios desses remanescentes e, na medida do possível, contribuirmos para reconstituição da "identidade perdida" dos ascendentes dos indígenas que ali habitaram.

\subsection{Aldeinha: onde múltiplas vozes e múltiplos sentidos se encontram}

A comunidade conhecida como Aldeinha, localizada numa região afastada do centro da Missão do Sahy, acaba sendo um elo dos atuais moradores com os povos tradicionais que ali viveram isolados até a chegada dos missionários no século XVII.

Os indícios da presença indígena estão registrados na historiografia regional, nos relatos orais e até mesmo em estudos da $7^{\text {a }}$ Superintendência Regional do Instituto do Patrimônio Histórico Artístico Nacional (IPHAN), realizado em março de 2008. As marcas de descendência nos estudos de Lourenço Silva (1915) aparecem quando afirma que "Sahy era uma aldeia de índios da tribo Pataxó para onde mais tarde ocorreram 
outros tipos de brancos e negros" (SILVA, 1915 apud DA PAZ, 2009, p. 79). Já o relatório técnico do IPHAN atesta que "[...] os colonizadores portugueses se deram conta de que as terras baianas já tinham donos: os indígenas. Foram providas então, diversas ações de extermínio contra eles que se espalhavam por diversas regiões do território da Bahia. Em Missão do Sahy não foi diferente" (IPHAN-7ªR, 2008, p. 2). O técnico responsável pela vistoria na Missão de Nossa Senhora das Neves do Sahy primeiramente apresenta um viés histórico, mas acaba destacando traços étnicos e outros aspectos de cunho arqueológico que indicam a presença indígena:

Os vestígios da presença indígena, contudo, apesar de raros, ainda podem ser percebidos na pele cabocla e no cabelo liso de muitos dos

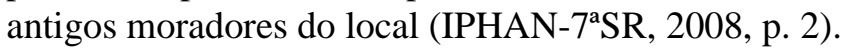

[...] boa parte da área residencial e do entorno de Missão do Sahy apresentam um considerável potencial arqueológico. A presença de vestígios arqueológicos aflorando à superfície em alguns pontos vistoriados é relativamente comum (IPHAN-7 ${ }^{\mathrm{S}} \mathrm{SR}, 2008$, p. 2).

No cemitério de Missão dos Sahy, um dos locais vistoriados, é o mesmo que outrora pertencia ao convento e que ainda hoje é utilizado pela população. [...] são encontradas ossadas de enterramentos ocorridos anteriormente, além de objetos muitas vezes relacionados à cultura indígena como cachimbos, utensílios de cerâmica, ornamentos e oferendas de caráter mortuário ritualístico (IPHAN-7 ${ }^{\mathrm{a}} \mathrm{SR}, 2008$, p. $3)$.

Somam-se a essas informações técnicas, presentes em relatório de órgão do Governo Federal, as memórias orais e registros fotográficos de espaços e achados arqueológicos. Ao entrevistar o jovem Urupês $^{3}$ (2011), essas memórias surgem em diversos momentos.

Objetos arqueológicos aqui existem muitos, porém, eles ficam em poder de pessoas que nós não temos acesso, ainda aqui na comunidade. Muitos deles já foram levados, não estão mais aqui. Temos registro de cachimbos ${ }^{4}$ encontrados a mais ou menos três a quatro metros de profundidade. Eles são ornamentados e confeccionados em barro, alguns deles têm até detalhes de rostos que rementem ao rosto do europeu (URUPÊS, 2011).

Quando questionado sobre a localização e preservação desse material, bem como algumas ruínas, informa que:

\footnotetext{
${ }^{3}$ Nome indígena que significa: um tipo de cogumelo ou "orelha de pau", também é uma coletânea de contos e crônicas de Monteiro Lobato. Usado de forma fictícia. Entrevista completa no link: http://www.youtube.com/watch?v=5W26CoQz5cA\&feature=youtu.be

${ }^{4}$ Fotografia de um destes cachimbos encontra-se anexada ao relatório do IPHAN, citado nas referências.
} 


\section{Edurañãa,EscolarSociedare}

Uma unidade de um desses cachimbos, com a réplica do rosto, está em poder de uma senhora daqui da comunidade. Existe outros dois, já num outro formato, mas com o mesmo material, mesma argila, em poder de uma outra pessoa daqui da comunidade também. Têm também fotografias, de cem, cento e cinquenta anos atrás, que mostram tanto esses objetos arqueológicos como mostram alguns pontos naturais que são os sítios arqueológicos (URUPÊS, 2011).

O Cemitério de Missão do Sahy que, além de alguns túmulos que tem hoje, cerca de cem, cento e cinqüenta anos de construção, nós temos ainda ruínas do muro que era do convento franciscano, ainda temos algumas ruínas, conservadas (URUPÊS, 2011).

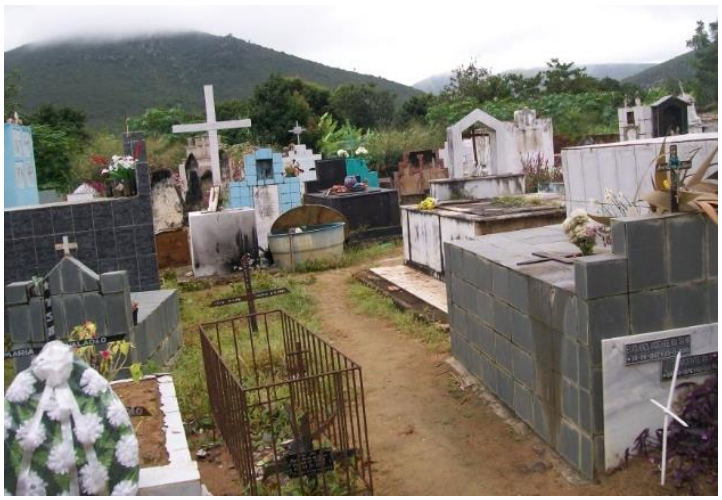

Figura 01 - Cemitério de Missão do Sahy Fonte: Acervo pessoal

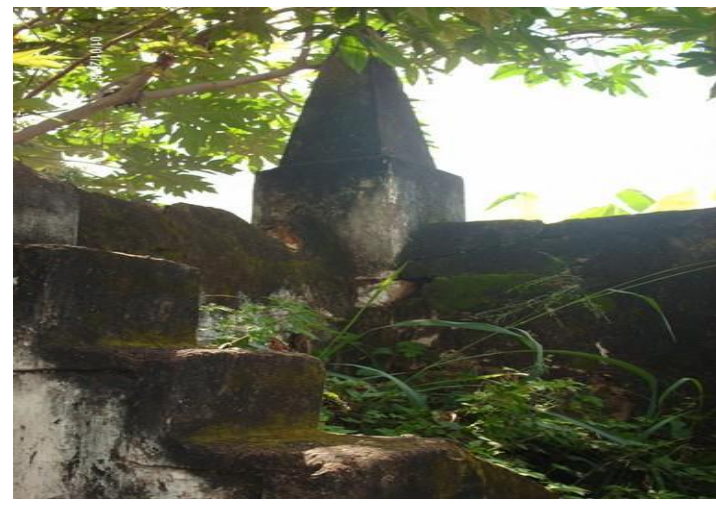

Figura 02 - Muro que separa cemitério e convento Fonte: Acervo pessoal

Todo esse patrimônio histórico material encontra-se ameaçado pela falta de preservação e pela falta de valorização da ancestralidade indígena. Falta, sobretudo, aos que se assumem como descendentes, um verdadeiro pertencimento étnico, pois é perceptível que os descendentes da Missão têm dificuldades de se autodefinirem como grupo étnico. Para os antropólogos, esses grupos têm como características "as formas de organização social em populações cujos membros se identificam e são identificados como tal pelos outros, constituindo uma categoria distinta de outras categorias da mesma ordem" (MONTAGNER, 2010, p. 34).

Assim, para que realmente se aceite uma etnicidade seja Pataxó, Kiriri e/ou Payayá é preciso somar aos registros históricos e as memórias orais um sentimento de pertencimento. Caso contrário, os que se foram continuarão sendo vistos como personagens de memórias remotas e os que se apresentam como descendentes seguirão, ora considerados sonhadores ora como aproveitadores. Essa última acusação quando a 
etnicidade supostamente puder render alguma vantagem pessoal para que se identifica como descendente dos povos originários que ali viveram.

Esse contexto de dúvidas e incertezas acaba contribuindo para que as controvérsias que cercam a localidade da Aldeinha sejam reais e atuais, mesmo diante de todo um processo de reconstrução étnica e social que alguns poucos moradores da localidade vêm intentando alcançar.

Voltando as origens da Aldeinha, além do nome fazer alusão a uma forma de organização geográfica dos indígenas, também traz uma carga semântica, histórica e socialmente reveladora para os descendentes indígenas da Missão do Sahy. Quanto ao primeiro aspecto - geográfico -, a própria disposição das residências remete a uma organização espacial das aldeias. No entanto, não fica evidenciada a intencionalidade de criação da Aldeinha como forma de preservação das origens dos povos tradicionais.

Os registros orais existentes foram confirmados pelas entrevistas realizadas por essa investigação. Os relatos obtidos apontam que a ocupação do espaço e a constituição da comunidade não se deram, a princípio, pela noção de pertencimento étnico. Deramse, sim, pelas necessidades pessoais de uma mulher diante da sua viuvez. Hoje, no entanto, existe a noção de pertença às origens tradicionais. Mesmo de forma enviesada, a depender dos interesses em jogo, aflora um irrestrito pertencimento à cultura ancestral.

Por conta dos assédios ocorridos nos últimos anos aos moradores da localidade e também por uma estratégia financeira, as entrevistas com a matriarca da Aldeinha se tornaram mais difíceis. Este deve ser o motivo pelo qual as produções acadêmicas consultadas (teses, dissertações, monografias e artigos - DA PAZ, 2004; DA PAZ E PAIVA, 2008; SANTOS, 2007; DOURADO, 2008; SANTOS E GONÇALVES, 2011; OLIVEIRA, 2012) voltadas para Missão dos Sahy pouco ou nada mencionam sobre a Aldeinha.

Em artigo científico de Santos e Gonçalves (2011), apresentado no VI Congresso Brasileiro de História da Educação - VI CBHE/Vitória-ES, as autoras trazem uma afirmação que explica os momentos de sonegação de informações por parte de moradores da Aldeinha:

Alguns destes fragmentos foram obtidos através das narrativas de sua matriarca, que a princípio contava com desenvoltura e orgulho como tinha criado aquele lugar onde reside com a sua família, mas hoje devido à procura de muitos curiosos sobre o assunto, a família e ela 
mesma não se dispõem mais a fornecer informações; os motivos alegados são os mais diversos, e vão desde a necessidade de preservação da intimidade coletiva da família, até a questão de obtenção de algum ganho extra com essas narrativas (SANTOS e GONÇALVES, 2011, p. 5).

Por outro lado, as poucas informações que existem sobre a origem da Aldeinha são de domínio público, assim, em uma das entrevistas essas reminiscências vieram à tona. Ao entrevistar Apoema $^{5}$ (2011), compreendemos o processo de formação da localidade e tivemos como entender a relação dos nativos com o artesanato de cipó.

Quem cumeçô tudo na tribo foi Edite ${ }^{6}$. Lá num tinha nada, era só mato. Mas dispôs que ficou sem marido levou seus fios tudo prá lá. Então fez umas taperazinha e foi arrumando, dispôs começo a fazer cesta e bonecas de palhinha pra pode vender e dá de cumé pra todo mundo (APOEMA, 2011).

Essa origem do nome é confirmada por Santos e Gonçalves (2011), ao evocarem a figura da senhora Edite Maria Arcanjo e atribuir a mesma a organização inicial, bem como toda condução da Aldeinha.

Segundo a matriarca, o local, afastado do centro do povoado, foi habitado por ela e seus filhos logo após o falecimento do seu esposo. Viúva e sem ter uma situação econômica que possibilitasse o sustento dos filhos menores, contudo sem querer doá-los para serem criados por algumas famílias de melhores condições, resolveu isolar-se e sobreviver daquilo que a mata poderia prover: a caça, a pesca, frutos silvestres, a comercialização do oricuri, uma espécie de fruto de uma pequena palmeira do sertão do Nordeste e a confecção de pequenos cestos de cipó (SANTOS E GONÇALVES, 2011, p. 4).

$\mathrm{Na}$ condição de pesquisadores, nossa aproximação com membros da Aldeinha foi mediada pelas ações docentes que desenvolvíamos no município de Senhor do Bonfim, BA. O vínculo com a Universidade e as ações de projetos que desenvolvíamos possibilitou o rompimento das barreiras iniciais que dificultavam a aproximação com os sujeitos e com as histórias da Aldeinha.

\footnotetext{
${ }^{5}$ Nome de origem indígena que significa: aquela que vê mais longe. Utilizado de forma fictícia para simbolizar uma mulher de 78 anos que consegue perceber todo processo histórico e analisar a situação atual.

${ }^{6} \mathrm{O}$ nome da matriarca foi mantido, pois é público sua identidade por conta da liderança que exerce, mesmo com seus 79 anos.
} 
A partir de então, a aproximação permitiu uma maior compreensão da organização desses descendentes de Edite que, por se assumirem como indígenas, marcam nas gerações que a procederam este traço étnico.

Quando da aproximação com membros da Aldeinha surgiu a informação de que existiam 52 habitantes dentre os quais 35 eram adultos e 17 eram crianças e adolescentes. Esses indivíduos estavam distribuídos em 10 famílias, sendo todos "filhos" da localidade. Os matrimônios deveriam seguir laços sanguíneos, portanto, eram comuns casamentos entre primos. Esta informação acabou apontando uma proximidade cultural com outras etnias indígenas, portanto, a temática foi explorada em uma entrevista com Upiara ${ }^{7}$, um dos filhos de Dona Edite. Na oportunidade, quando perguntado sobre os casamentos entre familiares, respondeu:

Sim, o casamento acuntece entre os primo. Entre irmão num pode e também num pode entre tios e subrinhos. Mas isso já tem tempo que num acontece. Hoje tá mais fácil casá com gente que não é dos Kariri (UPIARA, 2011).

- É verdade que quando se casa com alguém de fora não pode ficar na Aldeinha? Por que isso?

Tem uma meia verdade ai. Se se juntar com arguém de fora, pode ser que essa pessoa já tenha casa, trabalho e tudo mais, como é que vai largá tudo pra morar na Aldeinha? O que acontecia bem antes era que não tinha espaço aqui, intão se casasse fora fosse morar fora também. Mas sou da opinião que se puder casá com os daqui melhor. É gente nossa, gente que a gente conhece (UPIARA, 2011).

- Mas essa decisão com relação aos casamentos é por uma questão cultural?

Não, eu acho que não. As pessoas até fala que é para num misturar mais o sangue com quem não é índio, mas num é bem assim não. É mais pela coisa da moradia e do trabaío (UPIARA, 2011).

As respostas oferecem elementos importantes para se pensar a questão indígena na Aldeinha. Primeiro o pertencimento étnico que aparece na primeira e na última resposta, nesta última encontra-se presente a ideia de "misturação"8 dos indígenas. “Hoje é mais fácil casá com gente que não é dos Kariri”. Neste estudo, por meio de entrevista, foi a primeira vez que alguém da Aldeinha se assumiu como Kariri, ou seja, se auto identifica como descendente indígena.

\footnotetext{
${ }^{7}$ UPIARA: nome de origem indígena que significa: o que luta contra o mal.

${ }^{8}$ Termo utilizado por Maria do Rosário Carvalho, 1988 e João Pacheco de Oliveira, 1999.
} 
Por isso, ter consciência da condição indígena é fundamental para a determinação do pertencimento étnico. Assim sendo, o poder de auto nomeação das coletividades e a noção de respeito à alteridade são pontos a serem considerados nos processos de reconhecimentos das comunidades indígenas. Importante frisar que esses não são critérios fechados, e ainda, estes estão amparados pela Convenção 169 da Organização Internacional do Trabalho - OIT.

As possibilidades para que uma comunidade tradicional, como a Aldeinha, seja reconhecida passa também pela preservação e guarda de utensílios de antepassados, pela identificação de sítios arqueológicos que tenham valor histórico para a comunidade e que ajudem na identificação do território e no seu reconhecimento étnico. A Missão do Sahy conjuga todos esses fatores, no entanto, há um espalhamento desses elementos, o que dificulta tanto o autorreconhecimento quanto o reconhecimento externo/oficial da descendência indígena. É importante uma orientação dos órgãos indigenistas para que os moradores saibam que "é a capacidade de reconhecer no espaço fatos e locais vinculados à tradição de um povo que constitui o principal pré-requisito para o reconhecimento de alguém como membro daquela comunidade" (PARAÍSO, 1987, p. 14).

Quanto à mistura, quando se trata de populações descendentes de indígenas, não é raro o surgimento de falas como essa: "As pessoas até fala que é para num misturar mais o sangue com quem não é índio”. Isso não é uma especificidade da Aldeinha e dos parentes de Upiara. A misturação de indígenas, sobretudo no nordeste brasileiro, foi fruto de um processo histórico de desconstruções da cultura nativa através de atribuição de uma cultura introjetada pelos colonizadores.

As opções pelos casamentos consanguíneos como estratégia para romper com a misturação não é privilégio dos indivíduos da Missão do Sahy, outras etnias sofrem com o mesmo dilema. Todavia, mesmo com as dificuldades da FUNAI para reconhecer essa situação, isso não tem sido impeditivo para o reconhecimento étnico das comunidades.

Hoje, o maior problema não está nas relações de consanguinidade e, consequentemente, no autorreconhecimento e na aceitação da especificidade étnica. Os indígenas e descendentes se deparam com a dificuldade do Governo/FUNAI em reconhecer o "índio misturado" como índio, isso se deve ao não enquadramento de 
alguns povos no modelo de indígenas "puros", "primitivos", a exemplos dos povos tradicionais da Amazônia e do Xingu.

Por outro lado, é importante ter conhecimento de que os laudos antropológicos, sustentados pelas teorias do campo da cultura (identidade, hibridismo, diáspora), têm defendido o pertencimento étnico de diversos povos no Brasil. Um exemplo é o trabalho de Delvair Montagner (2007) sobre a construção da etnia Náwa, no Acre:

Podemos considerar as relações sociais entre o regional e o índio como sendo de igualdade, pois uma pessoa branca ao casar com uma índia ou mestiça índia, passa a se considerar ideologicamente igual ao parceiro: índio. [...] Os filhos de um casal assim misturado, apesar de terem uma parte de sangue de branco e outra de índio, são considerados da "raça" Náwa, pois "moram no mesmo lado" destes, em sua terra, nasceram e se criaram nela (MONTAGNER, 2007, p. $85)$.

No processo de criação do grupo étnico Náwa seus membros geraram uma cultura própria, buscando resquícios antigos dentro de um território delimitado, considerado de uso comum de seus antepassados. Elegeram como uma das marcas de indianidade cacos de cerâmica, materiais líticos, antigas capoeiras e cemitérios, sobre os quais todos concordam quanto a sua procedência histórica (MONTAGNER, 2007, p. 43).

As situações enfrentadas na Missão do Sahy e as descobertas sobre a cultura Náwa se aproximam substancialmente de uma das acepções de cultura apresentada por Stuart Hall (2003):

O que esses exemplos sugerem é que a cultura não é apenas uma viagem de redescoberta, uma viagem de retorno. Não é uma "arqueologia". A cultura é uma produção. Tem sua matéria-prima, seus recursos, seu "trabalho produtivo". Depende de um conhecimento da tradição enquanto "o mesmo em mutação" e de um conjunto efetivo de genealogias. Mas o que esse "desvio através de seus passados" faz é nos capacitar, através da cultura, a nos produzir a nos mesmos de novo, como novos tipos de sujeitos. Portanto, não é uma questão do que as tradições fazem de nós, mas daquilo que nós fazemos das nossas tradições. Paradoxalmente, nossas identidades culturais, em qualquer forma acabada, estão a nossa frente. Estamos sempre em processo de formação cultural. A cultura não é uma questão de ontologia, de ser, mas de se tornar (HALL, 2003, p. 44).

Na realidade investigada percebe-se que o retorno ao passado é uma forma dos sujeitos se perceberem como parte de um determinado grupo, porém, não basta apenas o rótulo de indígena para se pertencer a uma determinada comunidade, antes é preciso que 
os sujeitos se reconheçam com parte desta e serem por ela reconhecidos (CUNHA, 1986, p.11). Com isso, intenta-se que a mudança da descendente indígena Dona Edite para uma localidade afastada constituiu, mesmo que sem intenção, uma forma diferente de operar as tradições do seu povo, ou seja, operou a cultura enquanto produção social da vida. Tornou-se culturalmente descendente indígena e não apenas foi rotulada como tal.

Nesse processo de transformações e intermediações culturais muda-se toda uma estrutura de convivência social, retoma-se a cultura dos antepassados para se capacitar através das memórias e produzir a si mesmo novamente (HALL, 2003, p. 44). Por isso é que Dona Edite e seus descendentes - moradores da Aldeinha - buscam nas tradições dos antepassados o manejo do cipó e transformam esta atividade artesanal na principal fonte de renda da comunidade, além de criar o laço com os povos que lhes antecederam.

Por terem assumido a cultura como produção, transformando-a ao mesmo tempo em matéria-prima e recurso para o trabalho produtivo, Upiara considera que houve uma grande mudança no manejo do cipó e na relação dos descendentes com este labor.

\begin{abstract}
Antes só quem fazia os trançado era os home da família. Mas hoje mulher, menino todo mundo tomou o gosto pelo trabaí; Daqui todo mundo tira algum pro sustento da famiá. Hoje nós melhoremô muito os produto, tem mais variedade, agente usa não só o cipó caititu e o cajal, nois usa também o bambu e a taboca, tudo tirado das mata da região. (UPIARA, 2011).
\end{abstract}

As transformações produtivas e culturais também são consideradas nos estudos que Santos e Gonçalves (2011) realizaram na Aldeinha e corroboram as afirmações de que a cultura como devir precisa ser muito mais do que uma redescoberta, uma viagem de retorno às origens.

Com o melhoramento das técnicas até então primitivas, o artesanato foi criando o seu espaço de comercialização e transformando-se em renda principal desta comunidade familiar e a exemplo de outros produtos artesanais confeccionados por comunidades similares, os produtos por eles produzidos já são deslocados para outros espaços comerciais. Nesta comunidade são confeccionados inúmeros objetos como: caçoas, cestos, bicicletas e burricos decorativos, luminárias e móveis: banquinhos, namoradeiras, sofás entres vários outros. [...] estes produtos são comercializados nas feiras da região, na feira de Missão do Sahy e em feiras artesanais; além de receberem encomendas de todas as partes do país também já forneceram alguns produtos para fora do país. (SANTOS E GONÇALVES, 2011, p. 6). 


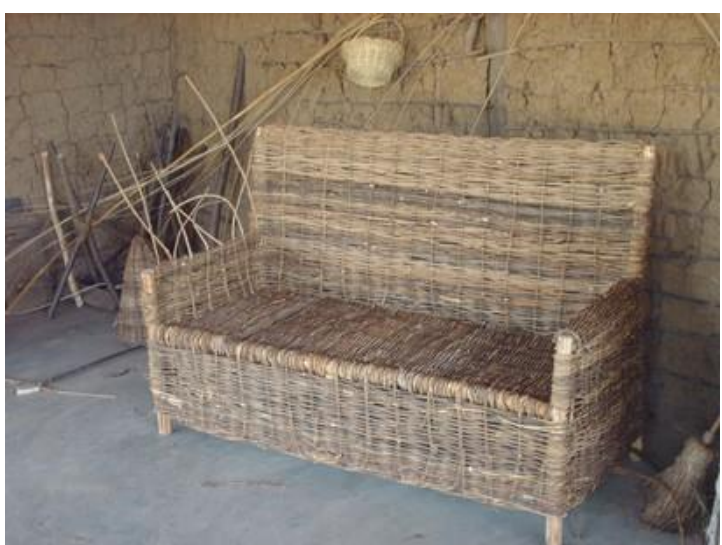

Figura 03 - Artesanato da Aldeinha - Sofá

Fonte: Acervo pessoal

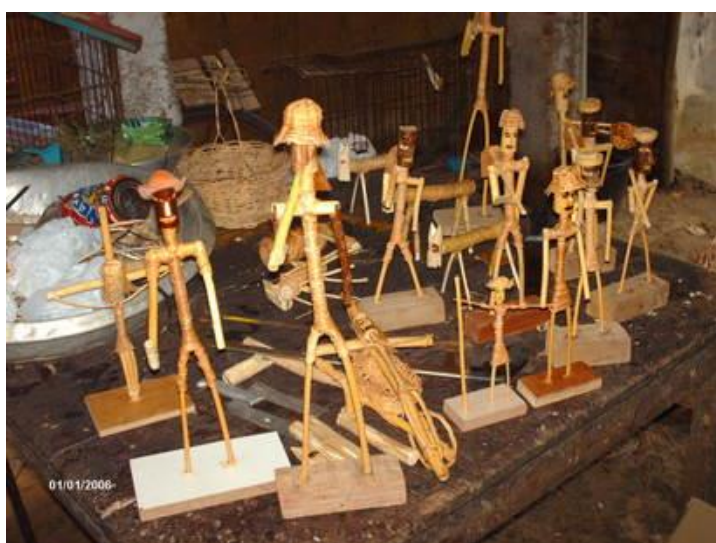

Figura 04 - Artesanato da Aldeinha - Bonecos

Fonte: Acervo pessoal

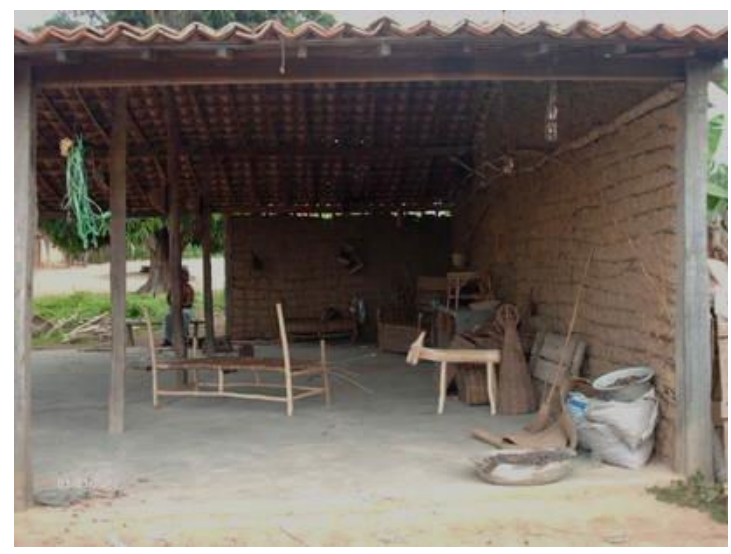

Figura 05 - Artesanato da Aldeinha - Ateliê Fonte: Acervo pessoal

Com os olhos cegos para a perspectiva transformadora da cultura poderia se cair na armadilha de dizer que os laços que ligam os descendentes indígenas as suas raízes estão fadadas à extinção, tendo como argumento para tal assertiva os poucos vestígios da história de descendência, a má preservação dos monumentos e sítios arqueológicos e a paulatina perda das memórias orais por conta da morte dos mais velhos, bem como por consequência do desinteresse das gerações mais novas. Todavia, o que mobiliza este estudo é reconhecer que existe sim todo esse (des) caminho cultural - ancorado nas teorias de misturação, aculturação, hibridismo - só que do outro lado existem os debates sobre reafirmação das identidades (individual e coletiva) e a perspectiva diaspórica da cultura, no entanto, nos valendo da mensagem dos versos de Carlos Drummond de Andrade $^{9}$, não se trata de decidir pela metade mais bela da verdade, trata sim de olhar para o problema direcionado pela "miopia" que nos faz seres culturais em permanente produção.

\footnotetext{
${ }^{9}$ Poema A Verdade. In.: ANDRADE, Carlos Drummond de. Antologia poética. 35. ed. Rio de Janeiro: Record, 1996. 276 p.
} 
A propósito da decisão pela "verdade mais bela" é oportuno lembrar o que disse Upiara (2011): “Tem uma meia verdade ai. Se se juntar com arguém de fora, pode ser que essa pessoa já tenha casa, trabalho e tudo mais, como é que vai largá tudo pra morar na Aldeinha?". Nossa investigação não se pauta na defesa de uma territorialização ou desterritorialização cultural, mas sim, em apresentar os resultados de uma ação investigativa que intentou contribuir para afirmação das memórias e das tradições dos povos que viveram na Missão do Sahy, por isso, mesmo com a limitação de laudas exigidas por uma publicação dessa natureza, seguiremos apresentando outras reminiscências da Aldeinha, a exemplo das suas lendas, fatos e festas, permeado por pressupostos teóricos dos Estudos Culturais e das perspectivas marxistas e bakhtiniana.

\section{Polifonia e polissemia: Missão do Sahy e o cruzamento de vozes e sentidos}

As vozes da ancestralidade que, mesmo silenciadas pelo tempo e por outros agentes, seguem ecoando em Missão do Sahy tem a marca da cultura popular. De acordo com Maria da Glória da Paz (2004 e 2009) a cultura popular da localidade, que inclui cantos, lendas, danças, religiosidade, brincadeiras, jogos etc. é variada e ampla. Relatos como o do Curupira, da Mãe d'Água e as lendas dos túneis que iam dar em minas de ouro são comuns entre os mais velhos.

Também em sua religiosidade, o povoado é bastante pródigo. O catolicismo, trazidos pelos fundadores do aldeamento é marcante: as festividades da padroeira se dão em Agosto (mês em que o aldeamento foi elevado à Vila); há as construções de Igrejas e capelas (que segundo os moradores foram feitas pelos indígenas), como o do Monte Tabor e a capela que fica na praça; a tradição dos penitentes, durante a Semana Santa, que saiam do cemitério invocando o perdão divino, a peregrinação ao monte Tabor, as rezas e cantos aos mortos (as "incelenças" e o Reisado, na época de Natal). A religiosidade ancestral também está presente, embora fundido com elementos católicos e africanos, nos terreiros de candomblé, evidenciados pelos muitos despachos nas águas da "Pedra da Baleia", uma cachoeira próxima. Há também a presença de evangélicos, notada sobretudo por conta dos seus templos na comunidade.

Entre as brincadeiras e jogos infantis relatados pelos trabalhos citados encontram-se aquelas relacionadas à preparação das meninas para a vida matrimonial (boneca, quitute) e outras como a roda (que hoje é dita como manifestação folclórica do lugar), o esconde-esconde e amarelinha. 
Focando a história e os aspectos culturais o que nos mobiliza não é um "resgate cultural", muito menos implantar algo que esteja fora da base constitutiva desses indivíduos. Muito menos buscamos, como diz Gramsci (1978, p. 95), criar uma nova cultura, pois isso, não significa apenas fazer individualmente descobertas 'originais'. Para Gramsci, criar esse algo novo "significa também e, sobretudo, difundir criticamente verdades já descobertas, 'socializá-las' por assim dizer; e, portanto, transformá-las em uma base de ações vitais, em elemento de coordenação e de ordem intelectual e moral" (GRAMSCI, 1978, p. 96).

A partir desse sentido gramsciniano é que nos valemos dos procedimentos metodológicos relacionados à história oral para a operacionalização da investigação. Por sua vez, buscamos ancoragem nas discussões acerca da dimensão cultural do ser humano em nos processos dialógicos. Dessa forma, tornou-se possível compreendermos os múltiplos sentidos (polissemia) contidos nas várias vozes (polifonia) dos sujeitos.

A história oral se constituiu num instrumento de fundamental importância no resgate da história local e na compreensão de determinados elementos culturais no povoado. São essas histórias de vida, principalmente dos mais idosos, que nos ajudou a compor as informações sobre algumas vivências aparentemente desaparecidas da comunidade, suas crenças e seus aspectos culturais.

Essas histórias direcionaram nossos olhares para a dimensão cultural do ser humano e para os processos de constituição das identidades. Entendemos que não bastou olharmos para os resultados dos nossos diálogos com os remanescentes, mas, atentar para ações vitais que ali existem nos permitiu uma visão ampliada da realidade. Foi então que percebemos que na localidade existe um problema de negação de direitos, mas, é justamente por essa negação existir que está colocada a possibilidade de superação. Para reforçar a convicção de que será a partir do processo de negação social e autonegação da identidade indígena que será possível um processo de superação, buscamos ancoragem em Marx (1982): “A humanidade só se propõe às tarefas que pode resolver, pois, se considerar mais atentamente, se chegará à conclusão de que a própria tarefa só aparece onde às condições materiais de sua solução já existem, ou, pelo menos, são captadas no processo do seu devir”. (MARX, 1982, p. 25)

Esse processo de negação automaticamente nos remete à Marx (1982) quando este nos diz que as formas de organização da sociedade se enraízam nas relações 
materiais de vida. A partir dessa afirmação é pertinente sabermos que, "Na produção social da própria vida, os homens contraem relações determinadas, necessárias e independentes de sua vontade, relações de produção estas que correspondem a uma etapa determinada de desenvolvimento das suas forças produtivas materiais. " (MARX, 1982, p. 25).

Assim, em Missão do Sahy, a produção social da vida dos indivíduos não foi uma escolha dos mesmos. O contexto histórico, político e social, marcado pela exploração do homem e das riquezas acabaram por condicionar os modos de organização social e espiritual dos remanescentes indígenas.

No desafio de viver essa realidade numa dimensão investigativa consideramos necessário assumir que é nas relações sociais que nos constituímos e contribuímos para constituição do outro, assim como o outro contribui nossa constituição. Esse é o caráter mútuo da constituição, onde se abre a possibilidade de transformarmos o conjunto da sociedade e sermos por esta transformados.

Essa dimensão social e de contradição que constitui as relações sociais de classe traz consigo o movimento de afirmação/negação/afirmação das transformações individuais e coletivas, pois tratam-se de relações contraídas-vividas no seio de uma sociedade de contradição. Por isso continuamos a ouvir Marx ao dizer que, "Em uma certa etapa do seu desenvolvimento, as forças produtivas da sociedade entram em contradição com as relações de produção existentes. [...] Sobrevém então uma época de revolução social (MARX, 1982, p. 27-28).

Apresentamos essas assertivas para demarcarmos a necessidade dos remanescentes dos Kiriris e Payayás e perceberem a importância histórica e antropológica do seu ser social. Tomada essa consciência abre-se a possibilidade de romperem os grilhões e conduzirem uma transformação individual e coletiva da sua condição/negação étnica.

Nesse processo de contribuição para o fortalecimento da identidade indígena buscamos em Gramsci (1981) ancoragem que nos permita descobrir que homem é esse que estamos tratando. Gramsci diz que o homem é o processo de seus atos; que os homens podem ser criadores dos seus próprios atos ao pensar sobre si mesmo e sobre/com os outros, pois a "humanidade que se reflete em cada individualidade é composta por diversos elementos: o indivíduo; os outros homens e a natureza" 
(GRAMSCI, 1981, p. 35). A contradição constitutiva está presente na intersecção desses elementos, travando uma luta para superar os processos de negação da identidade indígena.

Esse processo em que ocorrem as contradições constitutivas nos levam a pensar: quem é o homem/indígena? O que ele pode se tornar nesse processo constitutivo de contradição? Buscando fortalecer a visão de homem, numa perspectiva históricocultural, nos valemos de alguns questionamentos de Vygotsky (1989, p. 33): "O que é o homem? Para Hegel é o sujeito lógico. Para Pavlov é a soma, organismo. Para nós é a personalidade social é o conjunto de relações sociais, encarnado no indivíduo".

Antônio Gramsci (1981), também nos oferece subsídios para análise/construção acerca da essência do homem quando nos diz que: "Se observarmos bem, veremos que - ao colocarmos a pergunta 'o que é o homem' - queremos dizer: o que é que o homem pode se tornar, isto é, se o homem pode controlar seu próprio destino, se ele pode 'se fazer', ele pode criar sua própria vida" (GRAMSCI, 1981, p. 38). Portanto, para o autor o homem precisamente o processo de seus atos. Acreditamos assim que, estamos no/com o mundo para sermos criadores de nós mesmos e da nossa vida. Igualmente acreditamos que o outro é criador de si mesmo e da sua vida numa dinâmica recíproca e simultânea que ocorre nas/com as relações sociais.

Essa certeza acerca dos processos constitutivos do homem e da sociedade nos mobilizou para instaurarmos um diálogo como os remanescentes indígenas da Missão do Sahy. Não nos instauramos qualquer diálogo, nos valemos sim, de um processo dialógico em que não ocorresse somente uma alternância de falas, mas, sobretudo, optamos por uma dialogia sustentada por um processo intencional de significações. Para tanto, buscamos nas construções de Bakhtin aportes que orientaram nossas incursões pela história oral.

Para o autor durante o processo de comunicação verbal ocorre um confronto, através do qual, uma das unidades "é determinada pela alternância dos sujeitos falantes" (BAKHTIN, 1997a, p. 239). Dualidade/alternância entre sujeitos que, para ser dialógica, precisa representar o que Bakhtin denomina de o todo real da comunicação (BAKHTIN, 1997a). No todo real é expresso que: 
responsiva ativa: ele concorda ou discorda (total ou parcialmente), completa, adapta, apronta-se para executar. E esta atitude do ouvinte está em elaboração constante durante todo o processo de audição e compreensão desde o início do discurso, às vezes já nas primeiras palavras emitidas pelo locutor. A compreensão de uma fala viva, de um enunciado vivo é sempre acompanhada de uma atitude responsiva ativa; toda compreensão é prenhe de resposta e, de uma forma ou de outra, forçosamente a produz: o ouvinte torna-se o locutor. (BAKHTIN, 1997a, p. 290)

Como o todo real da comunicação compreende um processo de significação, torna-se necessário pensar no papel do signo dentro do processo dialógico. De acordo com Bakhtin, o signo resulta de um consenso entre indivíduos socialmente organizados no decorrer das relações sociais. Assim, "as formas do signo são condicionadas tanto pela organização social de tais indivíduos como pelas condições que a interação acontece. Uma modificação destas formas ocasiona uma modificação do signo". (BAKHTIN, 1997b, p. 44).

Mediados por esses processos constitutivos que partem do diálogo é que apresentamos a seguir alguns dados construídos a partir do uso da história oral em Missão do Sahy. Em seguida optamos por já traçarmos algumas considerações acerca do vivido junto com os remanescentes indígenas.

\section{Diálogos, Narrativas e Percepções}

Alguns moradores mais antigos, bem como moradores que buscavam reconstruir a história dos povos originários da localidade, já tinham revelado alguns vestígios e fatos que ligavam os povos Kiriris e Payayás à Missão do Sahy. Contudo, precisávamos saber como esses conhecimentos alcançavam os alunos, professoras e outros membros da comunidade. Assim, estabelecemos alguns diálogos com esses sujeitos, tanto na Escola Municipal Antônio Bastos de Miranda quanto na Organização não Governamental Casa do Aprendiz Urupês, com alguns moradores.

\section{ENTREVISTADORES: O que você conhece sobre a história da Missão do Sahy?}

ALUNO: Minha vó, ela contava uma história da Missão pra gente, quando era pequeno eu e meus primos né? E ela falava que Missão começou quando surgiram os jesuitas, né? Aqui em Missão, que vinhero conhecer o lugar pra trazer a linha de ferro é a catequese pra cá. E então conhecero uma aldeia de índio e nessa aldeia tinha um índio cacique que o nome dele era Sahy, né? Tinha uma índia, o nome da índia eu não me lembro o nome. E por motivo do nome do indio ser Saí, os catecistas botaram o nome de Missão do Sahy, e ficou conhecida como Missão do Sahy. 
PROFESSOR: Eu sei tudo aquilo que todo mundo sabe, não é? Que a Missão foi onde tudo começou, não é? Daqui foi onde surgiu Bonfim; tudo, tudo o que a gente sabe, que todo mundo sabe. As lendas, aquelas histórias de sempre, o artesanato, quem passou por aqui nè? Os franciscanos, alguns dizem que foi os jesuitas mas na verdade foi os franciscanos num é isso? Esses lances todos assim, a gente sabe não é? Sempre que a gente faz algum evento aqui na escola, a gente procura principalmente o folclore, a gente procura trazer o pessoal daqui, que sabe alguma coisa que ainda tem. Trazemos aquelas senhoras que cantam rodas, que sabem a história da Missão.

Percebe-se que a perspectiva histórica está presente no imaginário popular que, por sua vez, foi passado de geração para geração por meio das histórias orais. Outro aspecto que destacamos é a ausência de proximidade do aluno com os seus ascendentes indígenas, pois, em nenhum momento menciona serem esses indígenas seus parentes.

Na visão do Professor percebemos uma mistura de crenças e dúvidas. Ao mesmo tempo em que recorre a fatos históricos acaba colocando-os em cheque, como se precisasse de um suporte para validar seus conhecimentos. Uma tentativa dessa validação, por meio da escola, fica evidenciada nas relações estabelecidas com as senhoras mais velhas. Estas sempre são convocadas para falarem dos processos culturais dos antepassados. Voltamos então à Marx para afirmarmos que "[...] A essência do homem não é uma abstração que pertença a um indivíduo específico. Em sua realidade ele é o conjunto de todas as relações sociais" (MARX, 1999, p. 78). São esses indivíduos os responsáveis pela retomada dos fatos e crenças que poderão demarcar a identidade de sua etnia.

Percebendo essa necessidade de retomada histórica, dentre vários episódios que foram narrados na investigação, tivemos que optar para essa publicação por alguns momentos dialógicos que demonstram a riqueza dessas percepções acerca dos Padres, dos antepassados, dos indígenas e dos saberes populares.

\section{ENTREVISTADORES: Quem aqui na Missão sabe da história dos Padres?}

SENHORA 1: Aqui na Missão eu só lhe digo isso, só pode ser Dona Madalena e tinha outro aqui que se fosse vivo lhe dizia tudo, sabe quem era? O finado Caboco, esse sabia de tudo, esse sabia de muita coisa, e aqui na Missão os mais veio já se acabaro tudo. De mais veio agora só tem Dona Madalena e Dona Isaura e uma veia ali de cento e tantas também, mas essa num é daqui, já mora em outro lugá.

\section{ENTREVISTADORES: Mas, Dona Isaura toda vida morou aqui?}

SENHORA 1: Não, foi pra Saúde, depois São Paulo.

ENTREVISTADORES: O povo daqui tem ligação grande com o distrito de Saúde, não é? 
SENHORA 1: É porque diz que esses zezuíta fugira pra lá, num sei como foi, eles sairo fugido daqui pra Jacobina. Dento de vinte e quato hora eles tivera que sair daqui. Dero vinte e quato hora pra eles saire daqui. O povo mais antigo tinham a mania de dizer que eles sairo por debaixo do chão.

SENHORA 2: Mas isso aí é mentira...Diz que tem esse tune que vai daqui até Jacobina.

ENTREVISTADORES: E esse túnel existe mesmo?

SENHORA 1: Diz o povo que tem, agora se tem eu num sei, diz que os Pade tinha que pegar água da cachoeira ia pela túne.

\section{ENTREVISTADORES: E os parentes da senhora, são daqui mesmo?}

SENHORA 1: eu ouvia falar porque minha mãe contava mais meu pai...que meu pai nasceu na Saúde, mas foi quase criado aqui na Missão também e minha mãe também.... A minha mãe, era caboca... Sabe o que que é caboca? A minha vó, mãe da minha mãe, foi caboca pegada na Saúde...botara os cachorro pra pegar ela no mato ela mocinha com 14 ano. Pegaro ela levaro pra saúde, os caboco foro lá pra pegar ela de volta e o pessoal num deixara e criaro ela. A mãe da minha mãe, minha vó, caboca mesmo do mato do lado da Saúde, depois veio pra ca, pra Campo Formoso.

\section{ENTREVISTADORES: O que a Senhora sabe sobre os índios?}

SENHORA 3: Aqui já tinha Índio os Tapa... Tapajós...Pataxos...os índios foi quem fizeram a igreja da Missão, a igreja da Missão era de taipa, toda de taipa, foi eles quem fizero. Diz que uma vez robaro o Senhor Morto pra Salvador e eles foro buscar esse Senhor Morto em Salvador. E trouxera de volta. A capela do monte, foi eles que fizera. A que tem hoje não é a mesma, caiu a que eles fizero. A antiga tinha o quarto do Santo nera cumade? E do lado tinha outro quarto das promessas, o pessoal botava as promessas, moletas, pernas, braço, num tem mais nada. Era perna, cabeça era tudo e jogaro tudo fora. O pessoal tinha umas taias de colocar água pra beber na sexta-feira Santa. Eu sei que a Missão é muito é velha. É mãe de Bonfim e num é bem zelada, como devia ser pela cidade de Bonfim que é grande né?

\section{ENTREVISTADORES: É verdade que a sabedoria dos antigos era muito grande?}

SENHORA 2: Meu bisavô, tirava tudo quanto era doença das pessoas sem precisar maltratar e nem cobrava dinheiro nada. Era aduvinhão. Aduvinhava tudo e dos índios não cobrava nada. Até que um dia andou uns... cume que chama de Salvador? Esse negoço de macumbero do Reconco (Recôncavo) e tomou todos os encantados do meu avô, disse que ele passou três dias manifestado com um negoço na mão, cum zoio fechado, só pra riba e pra baixo, estrada acima e estrada abaixo, cantando:

\section{ê, ê. ê. ê,ê. Indé/}

dê qui num dê, qui nun dá $\hat{e}, \hat{e}, \hat{e}, /$

$\hat{e}, \hat{e}$, indé / dê qui nun venha cá /

dê qui nun dê. qui nun dê / dê qui nun dê, qui nun dá /

é, $\hat{e}, \hat{e}, \hat{e}, \hat{e}$, indé / de qui nun venha cá...

Esses conhecimentos populares acerca dos remanescentes indígenas fortalecem os aspectos históricos e delineiam os processos identitários da comunidade. Essas histórias de vida são fontes que ligam o passado e o presente; que possibilitam 
conhecermos os modos de agir de ontem e hoje dos descendentes dos Kiriris e Payayás. Como esse dessilenciamento abrimos a possibilidade de constituição critica desses sujeitos e não só a formação de homens-massa.

Nessa perspectiva crítica Antônio Gramsci contribui conosco ao dizer que: "Quando a concepção do mundo não é crítica e coerente, mas ocasional e desagregada, pertencemos simultaneamente a uma multiplicidade de homens-massa" (GRAMSCI, 1981, p.94).

Muitas outras significações foram possíveis a partir dos diálogos estabelecidos com diferentes moradores de Missão do Sahy, bem como a partir dos estudos e historiografia sobre a localidade. Mas, a complexidade das falas, bem como as análises que a partir delas realizamos necessitaria de um veículo de comunicação que permitisse uma escrita mais detalhadas. Contudo, o importante espaço oferecido pelo Dossiê Educação, Saberes Tradicionais e Populares já permitiu apresentarmos um recorte satisfatório de nossa investigação.

\section{Considerações Finais}

São histórias como as narradas para essa investigação e outras já realizadas em Missão do Sahy que vem apontando os caminhos e as interpenetrações das culturas. Para os mais jovens retomar a história dos seus antepassados e relacioná-las com aspectos cotidianos, vem se constituindo em possibilidades de fortalecimento da identidade indígena. Entendemos que esse processo se dá através da construção de significados que, por sua vez, é parte de um atributo cultural, ou melhor, faz parte de um conjunto de atributos culturais inter-relacionados.

Nesse sentido, aquilo que os mais velhos pensam dos aspectos relacionados a vida da Missão do Sahy não podem ser considerados como simples estórias. São sim, memórias fundamentais para que o pertencimento indígena seja assumido, e assim, facilite o reconhecimento público da comunidade enquanto remanescentes dos povos Kiriris e Payayás.

Percebemos que o diálogo é o elo necessário para que as histórias de vida possam emergir e também apontar o nível de conhecimento dos indivíduos acerca dos contextos que marcaram a vida dos antepassados. Dessa forma, os sujeitos acabam se imbricando num processo constitutivo onde a diversidade cultural se faz presente e 
acaba por proporcionar novas significações acerca do pertencimento indígena e, consequentemente, vem possibilitando o surgimento de novas identidades.

Por fim, concluímos que, mesmo não sendo possível apresentar nesse artigo a totalidade da investigação realizada, os resultados que aqui apontamos nos indicam que os sujeitos ascendentes dos indígenas da Missão do Sahy estão tendo oportunidade para construírem novas versões de si mesmos e do seu passado. Acreditamos que esse pertencimento étnico poderá apontar perspectivas não só para os sujeitos que ascendem dos Kiriris e Payayás, mas, para a comunidade como um todo.

\section{Referências}

BAKHTIN, Mikhail. Estética da Criação Verbal. São Paulo: Martins Fontes, 1997a.

BAKHTIN, Mikhail. Marxismo e filosofia da linguagem. São Paulo: Hucitec, 1997b.

CUNHA, Manuela Carneiro da. Antropologia do Brasil: mito, história, etnicidade. São Paulo: Brasiliense: EDUSP, 1986.

DA PAZ, Maria Glória. Histórias e educação de mulheres remanescentes de Missão do Sahy. Tese (Doutorado em Educação). Universidade Federal do Rio Grande do Norte, Centro de Cincias Sociais Aplicadas. Natal: 2009.

DA PAZ, Maria Glória. Colégio Estadual de Missão do Sahy: os olhares de uma escola sobre um antigo aldeamento. Dissertação de Mestrado. Universidade de Québec. Canadá, Chicoutimi, 2004.

DA PAZ, Maria da. PAIVA, Marlúcia Menezes. Memórias e Práticas Religiosas de Senhoras Remanescentes de Missão do Sahy, no Piemonte da Chapada Norte da Diamantina, Bahia, Brasil. In: VII Congresso LUSOBRASILEIRO de História da Educação. 2008.

DOURADO, Maria das Neves A. Currículo, narrativas e oralidade: A história de vida de D. Terezinha e as contribuições para o currículo da Escola Municipal Antônio Bastos de Miranda Missão do Sahy. Monografia (Curso de Pedagogia). Universidade do Estado da Bahia (UNEB, Campus VII), 2008.

FREITAS, Edith Alves de A.; SILVA, José Freitas da. História da Freguesia Velha de Santo Antônio - Campo Formoso. 1997

FREITAS, José. A serra resplandecente. Campo Formoso: Gráfica JMA, 2001.

GADOTTI, Moacir. Pedagogia da Terra: ideias centrais para o debate. In: I Fórum Internacional sobre Ecopedagogia. Faculdade de Psicologia e Ciências da Educação Universidade do Porto - Portugal - 24 a 26 de março de 2000.

GONÇALVES. Esmeraldo Lopes. Opara - Formação Histórica e Social do Submédio São Francisco. Juazeiro:[s.e], 1997. 
GRAMSCI, Antonio. Concepção Dialética da História. Rio de Janeiro: Civilização Brasileira,

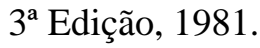

GRAMSCI, Antonio. Os intelectuais e a organização da cultura. $2^{\mathrm{a}}$ ed. Rio de Janeiros; Civilização Brasileira, 1978.

HALL, Stuart. A identidade cultural na pós-modernidade. $10^{\mathrm{a}}$ edição. Rio de Janeiro: DP\& A editora, 2006.

HALL, Stuart. Da diáspora. Identidades e mediações culturais. Belo Horizonte: ED UFMG, 2003.

IPHAN - Instituto do Patrimônio Histórico Artístico Nacional - $7^{\text {a }}$ Superintendência Regional. Informação Técnica 043/2008: Vistoria em Missão de Nossa Senhora das Neves do Sahy Senhor do Bonfim, BA, 2008.

MACEDO, Roberto Sidnei. A Etnopesquisa Crítica e Multirreferencial nas Ciências Humanas e na Educação. $2^{\mathrm{a}}$ Ed. - Salvador: EDUFBA, 2004.

MACHADO, Paulo Batista. Notícias e saudades da Villa Nova da Rainha, aliás, Senhor do Bonfim. Salvador: EDUNEB, 2007.

MARX, Karl. Para a Crítica da Economia Política: Salário, Preço e lucro, o rendimento e suas Fontes. Tradução de Edgar Malagod. São Paulo: Abril Cultural, 1982.

MARX, Karl. A Ideologia Alemã. São Paulo: Hucitec, 1999.

MINAYO, M. C. de S. O Desafio do Conhecimento: Pesquisa Qualitativa em Saúde. $2^{\text {a }}$. edição. São Paulo: Hucitec-Abrasco, 1999.

MONTAGNER, Delvair. Construção da etnia Náwa. Revista de Estudos e Pesquisas, FUNAI, Brasília, v.4, n.1, p. 33-108, jul. 2007.

OLIVEIRA, João Assis Silva. História de mulheres professoras: A História de Vida e Formação de Dona Vanda. (2012). Monografia (Curso de Pedagogia). Universidade do Estado da Bahia (UNEB, Campus VII).

PARAISO, Maria Hilda Baqueiro. Identidade étnica dos Xakriabá: laudo antropológico. Brasília: FUNAI, 1987.

SANTOS, Tatiane Patrícia da S. \& GONÇALVES, Valéria Macedo. Educação familiar: os valores transmitidos para as crianças remanescentes indígenas da comunidade de aldeinha de Missão do Sahy, Bahia. Vitória, ES. VI Congresso Brasileiro de História da Educação - VI CBHE, 2011.

SANTOS. Celmar Osório de M. S. dos. O Índio no imaginário de crianças de um povoado remanescente de antiga missão franciscana. Monografia (Curso de Pedagogia). Universidade do Estado da Bahia, (UNEB, Campus VII), 2007.

SILVA, Lourenço Pereira da. Memória histórica e geográfica sobre a comarca do Bonfim. Bahia: Lito-Tipografia Reis \& Cia, 1915.

VYGOTSKY, L. S. “Concrete Human Psychology”. Soviet Psychology. XXII, vol. 2. Tradução de A.A. Puzirei. 1989. 


\section{Fontes Orais}

URUPÊS: nome de origem indígena que significa: um tipo de cogumelo ou "orelha de pau", também é uma coletânea de contos e crônicas do escritor brasileiro Monteiro Lobato. Entrevista oral concedida aos pesquisadores.

APOEMA: nome de origem indígena que significa: aquela que vê mais longe. Entrevista oral concedida aos pesquisadores.

UPIARA: nome de origem indígena que significa: o que luta contra o mal. Trabalha com artesanato de cipó na comunidade conhecida como Aldeinha, fundada por sua mãe. Entrevista oral concedida aos pesquisadores. 